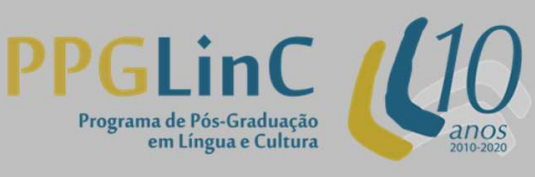

\section{AS CONSTRUÇÕES RELATIVAS NO PORTUGUÊS POPULAR DE FEIRA DE SANTANA-BA}

\section{RELATIVE CLAUSES IN THE SPOKEN PORTUGUESE OF FEIRA DE SANTANA-BA}

\author{
Silvana Silva de Farias Araújo ${ }^{1}$ \\ Universidade Estadual de Feira de Santana \\ Jéssica Carneiro da Silva ${ }^{2}$ \\ Universidade do Estado da Bahia
}

\begin{abstract}
Resumo: Apresenta-se o resultado do uso variável das construções relativas (CRel) na perspectiva da Sociolinguística em doze entrevistas da fala popular de Feira de Santana-BA. Objetivou-se descrever o português popular feirense e comparar o seu comportamento linguístico com o do português rural afro-brasileiro (BURGOS, 2003; RIBEIRO, 2009, LUCCHESI, 2015). Fixaram-se duas variáveis dependentes: i) relativização de termos não preposicionados relativas com lacuna e com lembrete, e ii) relativização de termos preposicionados - relativas pied piping e cortadoras. Verificou-se uso exclusivo do relativo que, poucas CRel com lembrete e predominância das cortadoras. Os resultados revelam que o português popular de Feira de Santana aproxima-se do comportamento linguístico observado nas comunidades rurais afrobrasileiras e distancia-se do português de Portugal (SILVA, 2011).
\end{abstract}

Palavras-chave: Sociolinguística; Construções relativas; Português popular feirense.

1 silvana.uefs.2014@gmail.com

2 jessxcs@gmail.com 
Abstract: This paper presents the results of relative clauses (CRel) variation from the perspective of Sociolinguistics presented in twelve interviews of the sample of spoken popular Portuguese in Feira de Santana-BA. It aimed to describe the Feirense popular Portuguese and compare its linguistic behavior with that of Afro-Brazilian rural Portuguese (BURGOS, 2003; RIBEIRO, 2009, LUCCHESI, 2015). Two dependent variables were set: $i)$ relativization of non-prepositional terms - relative with a gap and with a reminder, and ii) relativization of prepositional terms - relative to pied piping and cutters. There was exclusive use of the relative, few CRel with reminder and predominance of cutters. The results reveal that the popular Portuguese of Feira de Santana is close to the linguistic behavior observed in rural AfroBrazilian communities and is distant from Portuguese in Portugal (SILVA, 2011).

Keywords: Sociolinguistics; Relative clauses; Feirense popular portuguese.

\section{INTRODUÇÃO}

Este artigo apresenta o recorte da análise do uso variável das construções relativas (CRel) do português popular falado em Feira de Santana-BA SILVA; FIGUEIREDO; ARAUJO, 2017; SILVA, 2018). Esse fenômeno tem sido, com frequência, objeto de investigação em outros estudos, seja do português escrito, seja do português falado (TARALLO, 1983; BISPO, 2009; BURGOS, 2003; RIBEIRO, 2009; RIBEIRO; FIGUEIREDO, 2009) e, neste artigo, realiza-se uma descrição da variação no uso das estratégias de relativização da vertente popular do português feirense.

Dentre as CRel observadas no PB, encontram-se as relativas consideradas padrão: a relativa com lacuna ou neutra, de sujeito e objeto direto, portanto não preposicionada, em (1a); e a relativa pied piping, preposicionada, como em (1b); além de duas estratégias não registradas nas gramáticas normativas, portanto consideradas não padrão: são as relativas com pronome lembrete, como em (2a), e as relativas cortadoras, como em $(2 b)$ :

(1) a. O doce que comprei na padaria ontem estava muito gostoso.

b. Esse é o vestido com que saí ontem.

(2) a. O doce que comprei o/ele na padaria ontem estava muito gostoso. 
b. Esse é o vestido Ø que saí ontem.

Este estudo foi desenvolvido com o aparato teórico-metodológico da Sociolinguística Variacionista (WEINREICH; LABOV; HERZOG, 2006[1968]) e buscou descrever as possibilidades de relativização no português feirense, a fim de identificar se o comportamento linguístico das comunidades urbanas, em cuja formação não se tem tão marcadamente a presença africana, é o mesmo identificado nas comunidades rurais afro-brasileiras. A hipótese que norteia este trabalho, que tem como pressuposto o fato de que as peculiaridades do português falado no Brasil (PB) devem-se ao contato linguístico entre o português, as línguas indígenas e as línguas africanas, é que, no português feirense, as estratégias inovadoras sejam frequentes, considerando não só o contato, mas também a escolarização tardia no município, além dos contínuos processos migratórios ocorridos no município, com a vinda de muitas pessoas da zona rural, inclusive da de outros municípios.

\section{AS CONSTRUÇÕES RELATIVAS}

As orações relativas, denominadas pela tradição gramatical (LIMA, 1984; NEVES, 2000) de orações subordinadas adjetivas, modificam um nome, dando origem a um constituinte complexo ${ }^{3}$, que integra a oração principal ou matriz, como exemplificado a seguir:

(3) Os móveis que comprei__ _ chegam amanhã.

\footnotetext{
3 Sintagma constituído por um núcleo nominal modificado ou complementado por uma oração subordinada.
} 
Essa construção chama-se relativa por ser introduzida por um pronome relativo (que, no exemplo), cujas funções são: i) introduzir a oração encaixada, estabelecendo coesão sequencial entre duas orações; e ii) retomar o nome que o antecede, estabelecendo coesão referencial. Além disso, o pronome relativo exerce, na oração que introduz, a função sintática do termo relativizado.

Quando o pronome relativo exerce funções sintáticas que requerem preposição, o pronome relativo deve também ser precedido de preposição, deixando uma lacuna na posição de origem do sintagma preposicional relativizado, como no exemplo em (4). A esse tipo de relativas, Tarallo (1993) denominou de relativa pied piping.

(4) Todos compraram o livro [a que referi___durante a palestra].

Análises do PB demonstram que as estratégias indicadas como padrão pela tradição gramatical variam com estruturas consideradas não padrão. Tarallo (1983, 1993), que realiza uma pesquisa de cunho diacrônico sobre as relativas, diagnostica que, no PB, há três tipos de estratégias: i) relativa padrão ou relativa com lacuna, não preposicionadas e preposicionadas, como nos exemplos em (3) e (4), respectivamente; ii) relativa com pronome lembrete ou com a lacuna preenchida, como no exemplo em (5); e iii) relativa cortadora, como no exemplo em (6).

(5) Esse é o rapaz [que encontrei ele no restaurante com sua mãe].

O terceiro tipo de relativas encontrado no $\mathrm{PB}$, a relativa cortadora, varia particularmente com as relativas pied piping e consiste na não realização da preposição diante do pronome relativo, como se vê no exemplo em (6), a seguir. 
(6) Todos compraram o livro [que referi durante a palestra].

Os resultados dos estudos diacrônicos de Tarallo (1993, p. 88) revelaram, considerando as sincronias (1725, 1775, 1825, 1880), a ascensão da variante cortadora com o passar do tempo $(0,9 \%, 4,0 \%, 7,5 \%, 59,5 \%)$, e a queda das relativas pied piping $(89,2 \%, 88,1 \%, 91,3 \%, 35,4 \%)$, apontando para um provável quadro de mudança, com a substituição da estratégia padrão pela estratégia não padrão. Quanto às relativas com pronome lembrete, estas se mantiveram equilibradas, exceto na terceira sincronia $(9,9 \%, 7,9 \%, 1,3 \%, 5,1 \%)$ e apresentam um comportamento marginal no sistema sintático do PB. Os resultados de Tarallo (1993) quanto à variação entre a estratégia com lacuna e a com pronome lembrete nas estruturas de relativização de sujeito e de objeto direto, funções que não requerem preposição, apontam para a predominância das estratégias com lacuna em detrimento da estratégia com pronome lembrete.

Bispo (2009) analisou as estratégias de relativização em duas amostras de fala. A primeira amostra reuniu um total de 36 informantes do D\&G Rio de Janeiro, perfazendo 782 ocorrências de relativas, das quais $662(84,7 \%)$ eram do tipo padrão, incluindo as relativas preposicionadas, 14 (1,8\%) relativas lembretes e $106(13,5 \%)$ representavam as cortadoras em contraponto a $03(0,7 \%)$ ocorrências de relativa pied piping. A segunda amostra, constituída na cidade de Natal, é quantitativamente mais significativa que a primeira. $\mathrm{O}$ autor computou 1621 estruturas com relativas, das quais 1384 (85,4\%) eram de relativa padrão. No que diz respeito à variação nas estruturas relativas que requerem uma preposição, das 252 ocorrências encontradas, as cortadoras totalizam 210 (83\%) ocorrências, enquanto as relativas pied piping representam (17\%), 42 ocorrências.

Burgos (2003) também realizou uma pesquisa empírica sobre realização variável das relativas não padrão no português rural afro-brasileiro, considerando que o contato entre línguas ocorrido durante o período de 
colonização no Brasil teria interferido na aquisição do português. Seu corpus se constituiu a partir de amostras de fala da comunidade Helvécia, localizada no município de Nova Viçosa, estado da Bahia. Os dados de Burgos (2003) totalizaram 569 orações relativas. Chama atenção o fato de o autor não ter encontrado nenhuma ocorrência relativa pied piping e apenas 18 relativas com pronome lembrete. Em seu corpus, o autor computou 185 ocorrências de relativa cortadora.

Ribeiro (2009) também analisa as estratégias de relativização no dialeto rural afro-brasileiro do estado da Bahia, buscando explicar entre outros fatos o estatuto do que introdutor das sentenças relativas, considerando o contato do português com as línguas africanas. Seria um pronome relativo ou um complementador, como os que introduzem as orações substantivas e, portanto, não exerceria a função sintática na oração subordinada, estabelecendo apenas a coesão sequencial entre as orações? Essa discussão já havia sido realizada por Tarallo (1983) para o PB e por Brito (1991) para português europeu (PE). De acordo com Brito (1991, apud RIBEIRO, 2009), o que, nas construções de relativas de sujeito e de objeto direto, seria um complementador e a lacuna existente na sentença encaixada seria interpretada como uma categoria vazia ${ }^{4}$. Seria um pronome relativo nas construções em que são relativizadas as funções preposicionadas, relativas pied piping, e estabeleceria a coesão sequencial e referencial entre as duas sentenças, além de exercer função sintática na oração subordinada.

Ribeiro e Figueiredo (2009) analisaram o português escrito no século XIX por africanos alforriados, a fim de verificar se, no processo de aquisição de segunda língua, ocorre um comportamento semelhante ao observado no PB, presença das estratégias com pronome lembrete e da cortadora. Porém, os resultados demonstraram que o português desses africanos reflete a gramática

4 Sobre as categorias vazias, ver Mioto, Silva e Lopes (2004). 
portuguesa. Dentre as 17 ocorrências de relativa em funções preposicionadas encontradas no corpus, verificou-se apenas 01 de relativa cortadora. Na seção seguinte, detalha-se o quadro teórico-metodológico, incluindo a teoria e os métodos utilizados para a obtenção dos resultados.

\section{APORTE TEÓRICO-METODOLÓGICO}

No âmbito da Sociolinguística Quantitativa (WEINREICH; LABOV; HERZOG, 2006[1968]), postula-se a impossibilidade de estudar a mudança linguística fora da comunidade de fala. A mudança deve ser então compreendida considerando-se a vida social da comunidade de fala em que são produzidos os dados linguísticos, pois a língua sofre pressões e influências sociais constantemente. No caso deste trabalho, o contexto sócio-histórico em que se formou o PB assume um aspecto fundamental para se compreender o português falado em Feira de Santana-BA.

No que concerne à sócio-história do PB, Lucchesi (2001) salienta que o expressivo contato da língua portuguesa com os falantes de línguas africanas que adquiriram o português em situações precárias bem como a aquisição da língua portuguesa pelos imigrantes europeus e asiáticos, marcaram a história sociolinguística brasileira.

Sobre a sócio-história do município de Feira de Santana-BA, entende-se que os processos migratórios, a sua localização geográfica e seu poderio comercial resultaram em um intenso contato linguístico, possibilitado pelas pessoas que se deslocaram para Feira, com a finalidade de oportunidades de trabalho, troca comercial e busca de prestações de serviços médicos e educacionais especializados. Segundo Almeida, (2012, s. p.), as origens cidade “remontam ao século XVIII e a um passado eminentemente rural, caracterizandose por ser um lugar de pouso para viajantes, vaqueiros e suas boiadas, que 
vinham de toda a microrregião e até de outros estados". Para a autora, o contato linguístico em Feira de Santana ocorreu entre portugueses de diferentes localidades, paulistas, crioulos, descendentes de índios, e, atualmente, ocorre entre os dialetos nordestinos e, em menor escala, com outros dialetos. Por essas características peculiares, o município circunscreve-se como uma comunidade de fala singular, com a qual é possível destacar o entrecruzamento do contato rural com o urbano (ARAUJO; FREITAG, no prelo).

\subsection{A amostra investigada}

As amostras de fala analisadas pertencem ao acervo do Projeto A língua portuguesa do semiárido baiano - Fase 3: amostras da língua falada em Feira de Santana$B a$, sediado NELP5 ${ }^{5}$. Os informantes foram selecionados de acordo com as variáveis sociais apontadas no Quadro 1, a seguir:

Quadro 1: Fatores socioculturais utilizados na constituição da amostra do Projeto de Pesquisa A língua Portuguesa no Semiárido Baiano - Fase 3

\begin{tabular}{|c|c|}
\hline \multicolumn{2}{|c|}{ FATORES SOCIOCULTURAIS } \\
\hline \multirow{2}{*}{ Sexo } & Masculino \\
\cline { 2 - 2 } & Feminino \\
\hline \multirow{3}{*}{ Faixa etária } & Faixa I (25-35 anos) \\
\cline { 2 - 2 } & Faixa II (45- 55 anos) \\
\cline { 2 - 2 } Escolaridade & Faixa III (a partir de 65 anos) \\
\hline \multirow{2}{*}{} & Baixa ou inexistente \\
\cline { 2 - 2 } & Ensino Médio completo \\
\cline { 2 - 2 } & Ensino superior completo e/ou pós graduação \\
\hline
\end{tabular}

Fonte: adaptado de Araujo e Almeida, 2014, p. 35.

5 Núcleo de Estudos da Língua Portuguesa (NELP), do Departamento de Letras e Artes da Universidade Estadual de Feira de Santana (<http://www2.uefs.br/nelp/projetos.htm>). As entrevistas estão editadas em XML, por meio da ferramenta eDictor (<http://www.tycho.iel.unicamp.br/cedohs/corpora_o.html>). 
Para este estudo, foram consideradas 12 entrevistas realizadas com participantes da pesquisa, entrevistas estas que compõem parte da amostra do português falado em Feira de Santana-BA, distribuídos em três faixas etárias (4 informantes, 2 homens e 2 mulheres em cada). Após o levantamento dos dados, considerando as restrições estabelecidas ${ }^{6}$, foram fixadas duas variáveis, a variável dependente 1: relativa com lacuna versus relativa com lembrete; e a variável dependente 2: relativa pied piping versus relativa cortadora. As variáveis explanatórias consideradas para esta análise foram: o tipo do pronome relativo, a função sintática do relativo e a faixa etária7, já que as outras variáveis socais não mostraram um percentual significativo ou variável. Finalizados o levantamento e a codificação das ocorrências, os dados foram quantificados pelo programa computacional Goldvarb X (SANKOFF; TAGLIAMONTE; SMITH, 2005).

\section{$4 \quad$ A ANÁLISE DOS DADOS}

A quantificação dos dados referentes ao corpus analisado gerou um total de 522 dados. Na primeira, foram quantificadas todas as ocorrências de relativas encontradas no corpus. Na segunda rodada, foram analisados os dados referentes à variável dependente 1 e, na terceira rodada, os dados referentes à variável dependente 2. No corpus, verificou-se que as relativas não preposicionadas, como em (7), são mais frequentes do que as preposicionadas, como em (8a) e (8b), com $386(74 \%)$ e 136 ocorrências (26\%), respectivamente, um comportamento já observado em outros trabalhos sobre as relativas, tais como Tarallo (1993), Burgos (2003), Ribeiro e Figueiredo (2009), Lucchesi (2015b) e Oliveira e Ribeiro (2015).

6 Não foram consideradas as relativas livres, as reduzidas e as construções de clivagem.

7 Em um estudo maior (SILVA, 2018), foram consideradas um total de 13 variáveis explanatórias. Para este artigo, foram consideradas somente quatro variáveis (duas linguísticas e duas extralinguísticas), porque se fez necessário um recorte da pesquisa. 
(7) Só que tem um quarto no fundo [que eu fiz _ pa aluguel]. [INF01P.CA.F1.M] ${ }^{8}$

(8) a. Naquele tempo era uma companhia calma, tranquila, foi o tempo [em que a Feira tava crescendo]. [INF07P.F.F2.M]

b. Eu te digo uma coisa, teu irmão no bairro [Ø que eu moro] não pisa não. [INF01P.C.A.F1.M]

A seguir, são apresentados resultados da distribuição geral dos dados de acordo com as estratégias encontradas no corpus.

Tabela 1: Distribuição geral das construções relativas no português popular falado em Feira de Santana-BA

\begin{tabular}{lcc}
\hline Construções relativas & Ocorrências/Total & Frequência \\
\hline Relativa com lacuna & $380 / 522$ & $73 \%$ \\
\hline Relativa pied piping & $4 / 522$ & $1 \%$ \\
\hline Relativa cortadora & $118 / 522$ & $23 \%$ \\
\hline Relativa resumptiva/lembrete & $12 / 522$ & $2 \%$ \\
\hline Relativas de onde & $8 / 522^{9}$ & $1 \%$ \\
\hline
\end{tabular}

Fonte: elaborada pelas autoras.

Na Tabela 1, verifica-se que, a relativa com lacuna, estratégia considerada padrão, é bastante frequente no corpus. Porém, não se observa o mesmo resultado ao se focalizar a estratégia pied piping, também considerada padrão, em que o sintagma preposicionado é relativizado. São apenas 4 ocorrências, 1\% dos dados. Por outro lado, a estratégia cortadora é bastante frequente, $23 \%$ do total de dados. Contrariando a hipótese de que o português popular apresentaria um uso

8 Os códigos que seguem os exemplos possuem a finalidade de identificar o informante. Exemplo: [INF01P.CA.F1.M] = INF01 para Informante 2; P para norma popular; CA para o nome do (a) informante; F1 para Faixa 1; e M para sexo masculino.

9 Registram-se nessa tabela oito ocorrências de onde, porém foram encontradas 11 ocorrências. As 3 ocorrências restantes foram assim computadas: 1 pied piping, 2 com lembrete. 
frequente da estratégia com lembrete, uma quantidade pouco significativa dessa estratégia foi encontrada, apenas 12 ocorrências: 6 em função não preposicionada, como em (9), e 6 em função preposicionada, como em (10).

(9) Teve uma colega minha [que ela trabalha lá]. [INF04P.I.F1.F]

(10) Não tenho nada contra pagode e não tenho nada contra arroxa, mas é aquelas música [Ø que os jovem não vê letra naquelas música]. [INF03P.F1.M]

Quanto à relativização de um termo preposicionado, a estratégia mais frequente é a relativa cortadora, como em (11), com 118 ocorrências, um percentual de $23 \%$, seguida das relativas de onde, como em (12), com 8 ocorrências (2\%) e, por último, a relativa pied piping, como em (13), que ocorreu em 4 sentenças $(1 \%)$.

(11) Feira é o lugar [Ø que eu construí família], eu moro aqui há trinta anos. [INF08P.R.F2.F]

(12) Tem que procurar a estação de transbordo [onde tem um ônibus pa toda as localidades da cidade]. [INF05P.J.F2.M]

(13) Naquele tempo era uma companhia calma, tranquila, foi o tempo [em que a feira tava crescendo] aí pronto. [INF07P.F.F2.M]

A quantificação das estratégias de funções não preposicionadas, relativas à variável dependente 1, do português popular falado em Feira de Santana-BA pode ser visualizada na Tabela 2, a seguir. 
Tabela 2: Distribuição das construções relativas não preposicionadas no português popular falado em Feira de Santana-BA

\begin{tabular}{ccc}
\hline $\begin{array}{c}\text { Construções relativas não } \\
\text { preposicionadas }\end{array}$ & Ocorrências/Total & Frequência \\
\hline Com lacuna & $\mathbf{3 8 0 / 3 8 6}$ & $\mathbf{9 8 \%}$ \\
\hline Lembrete & $6 / 386$ & $2 \%$ \\
\hline
\end{tabular}

Fonte: elaborada pelas autoras.

Como se vê na Tabela 2, foram encontradas no corpus 386 ocorrências, das quais 380 são de relativa com lacuna, 98\% dos dados, ilustradas em (14) e 6 de relativa com lembrete, ilustrada em (15), com um percentual de $2 \%$ dos dados, revelando um quadro de não variação, ou seja, de uma regra semicategórica (LABOV, 2003).

(14) Acham que Feira é uma cidade [que_ não tem prestígio nenhum]. [INF02P.L.F1.F]

(15) Paco [que ele nãa tinha mãe], que ele era rico e não fazia questão do dinheiro dele. [INF04P.I.F1.F]

Quanto à variável 2, foram fixadas também 2 variantes, considerando apenas a presença versus a ausência de preposição: a relativa pied piping, como em (16) e a relativa cortadora, como em (17).

(16) A pessoa esquece por alguns aquele momento [em que ele tá alcoolizado]. [INF02.P.J.F1.M]

(17) Ouço só as musga evangélica [que (= de que) eu gosto muito]. [INF02.P.R.F1.F]

A distribuição dos dados da variável dependente 2 está registrada na Tabela 3, a seguir. 
Tabela 3: Distribuição das construções relativas preposicionadas no português popular falado em Feira de Santana-BA

\begin{tabular}{ccc}
\hline $\begin{array}{c}\text { Construções relativas } \\
\text { preposicionadas }\end{array}$ & Ocorrências/Total & Frequência \\
\hline Pied piping & $4 / 128$ & $3 \%$ \\
\hline Cortadora & $\mathbf{1 2 4 / 1 2 8}$ & $\mathbf{9 7 \%}$ \\
\hline
\end{tabular}

Fonte: elaborada pelas autoras.

Verifica-se, na Tabela 3, que, a estratégia considerada padrão é bem pouco realizada na fala popular de Feira de Santana-BA, confirmando a hipótese de que a baixa escolaridade favoreceria o uso da estratégia cortadora, considerada não padrão, indo ao encontro das pesquisas realizadas por Burgos (2003), Ribeiro (2009) e Silva (2011). No que diz respeito ao uso das cortadoras, os números registrados na Tabela 3 corroboram a hipótese de as relativas cortadoras substituírem a relativas pied piping (TARALLO, 1983).

\subsection{As variáveis explanatórias}

\subsubsection{Tipo de pronome relativo}

Essa variável foi fixada sob a hipótese de que o relativo que seria mais frequente, tendo em vista outros trabalhos sobre o tema, Burgos (2003) Ribeiro (2009), Ribeiro e Figueiredo (2009). No português popular feirense, ocorreram apenas os seguintes relativos: que, onde, ola que, conforme Tabela 4, a seguir.

Tabela 4: Distribuição da variável tipo de pronome relativo no português popular feirense

\begin{tabular}{ccc}
\hline Pronomes relativos & Ocorrência/Total & Frequência \\
\hline Que & $\mathbf{5 1 0 / 5 2 2}$ & $\mathbf{9 7 \%}$ \\
\hline Onde & $11 / 522$ & $2 \%$ \\
\hline Ola que & $1 / 522$ & $1 \%$ \\
\hline
\end{tabular}

Fonte: elaborada pelas autoras 
Os resultados registrados na Tabela 4 indicam que o relativo que é predominante no português popular feirense, confirmando a hipótese aventada. Esse relativo ocorreu em 510 relativas, o que corresponde a 97\% dos dados coletados, exemplificadas em (18), estando em concordância com outros trabalhos sobre as relativas no PB (BURGOS, 2003; RIBEIRO, 2009).

(18) Eu tenho um filho [que gosto muito desse filho]. [INF10.P.FC.F3.F]

Como se verifica nesta seção, o uso do relativo que é generalizado no corpus (510 das 522 ocorrências), substituindo os demais relativos. Esse uso generalizado de que corrobora a análise de Ribeiro (2009), ao apresentar o status de complementador, em todas as estruturas de relativização.

\subsubsection{Função sintática do pronome relativo}

Essa variável foi fixada sob a hipótese de que a posição de sujeito seria mais relativizada por ser mais acessível à relativização, conforme Keenan e Comrie (1977). Além disso, trabalhos realizados sobre o fenômeno no PB (RIBEIRO, 2008; RIBEIRO; FIGUEIREDO, 2009; LUCCHESI, 2015) têm registrado esse comportamento. Segundo Keenan e Comrie (1977), nas línguas naturais, nem todas as posições sintáticas estão disponíveis para serem relativizadas e há uma Hierarquia de Acessibilidade (doravante HA), associada à possibilidade de um SN ser relativizado a depender da posição que ocupa nessa hierarquia, representada no esquema em (19):

(19) Sujeito $>$ Objeto direto $>$ Objeto indireto $>$ Oblíquo $>$ Genitivo $>$ Objeto de comparação 
De acordo com Keenan e Comrie (1977, p. 66), há posições sintáticas mais passíveis de relativização do que outras, isto é, as posições à esquerda da escala (sujeito, objeto) são mais fáceis de relativizar do que as posições localizadas à direita (genitivo, oblíquo). A quantificação dos dados do português popular de Feira de Santana quanto à posição do termo relativizado revelou o seguinte resultado:

Tabela 5: Distribuição da variável função sintática do relativo nas construções relativas do português popular falado em Feira de Santana-BA

\begin{tabular}{ccc}
\hline Função sintática do relativo & Ocorrências & Percentual \\
\hline Sujeito & $\mathbf{2 4 5}$ & $\mathbf{4 7 \%}$ \\
\hline Objeto direto & $\mathbf{1 2 5}$ & $\mathbf{2 3 \%}$ \\
\hline Adjunto adverbial locativo & $\mathbf{4 7}$ & $\mathbf{9 \%}$ \\
\hline Adjunto adverbial de tempo & $\mathbf{3 6}$ & $\mathbf{7 \%}$ \\
\hline Objeto oblíquo & 34 & $\mathbf{6 \%}$ \\
\hline Outros adj. Adverbiais & 15 & $3 \%$ \\
\hline Complemento locativo & 12 & $3 \%$ \\
\hline Genitivo & 5 & $1 \%$ \\
\hline Predicativo & 3 & $1 \%$ \\
\hline TOTAL & $\mathbf{5 2 2}$ & $\mathbf{1 0 0} \%$ \\
\hline
\end{tabular}

Fonte: elaborada pelas autoras.

Observa-se, na Tabela 5, que as posições sintáticas não preposicionadas, sujeito e objeto direto, são as mais relativizadas, com 245 ocorrências, $47 \%$ do total de ocorrências, e 121 ocorrências, 23\%, respectivamente. Esse resultado também foi observado no português rural afro-brasileiro (BURGOS, 2003, RIBEIRO, 2009).

\subsubsection{A variável social: Faixa Etária}

A faixa etária é uma variável de bastante importância a qualquer estudo sociolinguístico, pois é por meio desse grupo de fator que se obtém considerações e justificativas coerentes a respeito de uma variação estável ou de uma mudança em progresso, de acordo com Weinreich, Labov e Herzog (2006 [1968]). A 
hipótese que se formulou, neste estudo, é a de que os informantes da Faixa I da variedade popular do português falado em Feira de Santana-BA fazem uso majoritário da relativa cortadora, ao contrário dos falantes da Faixa III. Os resultados referentes a esta variação estão dispostos na Tabela 6, a seguir.

Tabela 6: Distribuição da variável faixa etária na covariação pied piping versus cortadora no português popular falado em Feira de Santana-BA

\begin{tabular}{cccc}
\hline Faixa etária & Cortadora & Pied piping & Total \\
\cline { 2 - 4 } & Oc. $/ \%$ & Oc. $/ \%$ & Oc. $/ \%$ \\
\hline Faixa I (25-35 anos) & $\mathbf{6 2 / 1 0 0}$ & - & $62 / 48$ \\
\hline Faixa II (45- 55 anos) & $35 / 95$ & $2 / 5$ & $37 / 29$ \\
\hline Faixa III (acima de 65 anos) & $27 / 93$ & $2 / 7$ & $29 / 23$ \\
\hline Total & $\mathbf{1 2 4}$ & $\mathbf{4}$ & $\mathbf{1 2 8 / 1 0 0}$ \\
\hline
\end{tabular}

Fonte: elaborada pelas autoras

A Tabela 6 reflete que há mais ocorrência de relativa cortadora na Faixa I, ou seja, os informantes mais jovens realizam a relativa cortadora em maior frequência do que os informantes da Faixa II e Faixa III, com 62 ocorrências, do total de 124 cortadoras encontradas, referentes a 100\% dos dados. As ocorrências de relativa pied piping só ocorrem nas faixas mais elevadas. Dessa forma, há indícios da implementação da mudança linguística no sistema sintático do português feirense, assim como foi apontado por Tarallo (1993) a respeito do PB.

\section{CONSIDERAÇÕES FINAIS}

Com este estudo sobre as estratégias de relativização do português feirense, buscou-se discutir questões sociolinguísticas sobre a mudança linguística no PB, considerando a interferência da sócio-história do PB na constituição do falar feirense. Foram computadas no corpus analisado 522 ocorrências de relativas com antecedente, 386 de relativas não preposicionadas e 136 de relativas preposicionadas. Das relativas não preposicionadas, a maior parte (380) são de relativas com lacuna. Das relativas preposicionadas, as 
relativas cortadoras se sobressaem, com 117 ocorrências. De maneira pouco significativa, foram encontradas as estratégias da relativa com lembrete (6 ocorrências), da relativa pied piping (4 ocorrências) e da relativa cortadora com lembrete (6 ocorrências).

Os resultados obtidos com a análise quantitativa das estratégias de relativização encontradas na norma popular do falar feirense apontam para fatos bastante interessantes: i. o uso quase exclusivo do relativo que nas estratégias de relativização; ii. a ausência de variação entre as relativas com lembrete e as relativas com lacuna não preposicionadas; iii. a predominância das relativas cortadoras em detrimento das relativas pied piping (4 ocorrências apenas); e iv. a predominância da relativização das funções de sujeito e de objeto direto. Comparando esses resultados com os do português rural afro-brasileiro, verificase um comportamento bastante semelhante; predominância das relativas cortadoras (BURGOS, 2003; RIBEIRO, 2009; LUCCHESI, 2015b). Os resultados apresentados neste trabalho permitem ratificar a ideia de que o português brasileiro tem se distanciado do português europeu no que diz respeito às estratégias de relativização.

\section{REFERÊNCIAS}

ALMEIDA, L. F. de. Urbanização, escolarização e variação linguística em Feira de Santana-Bahia (século XX). Tabuleiro de Letras: Revista do Programa de Pós-Graduação em Estudo de Linguagens, Universidade do Estado da Bahia - UNEB, Departamento de Ciências Humanas - DCH I, n. 04, jun. 2012.

ARAUJO, S. S. de F.; ALMEIDA, N. L. F. de. O projeto A língua portuguesa no semiárido baiano - Fase 3: critérios de constituição e da amostragem do Banco de dados. In: FREITAG, R. M. Ko. (Org.). Metodologia de coleta e manipulação de dados em Sociolinguística. São Paulo: Edgard Blücher, p. 27-47, 2014.

BISPO, E. B. Estratégias de relativização no português brasileiro e implicações para o ensino: o caso das cortadoras. 2009, 162 f. Dissertação (Mestrado em Linguística). Universidade Federal do Rio Grande do Norte, Natal, 2009. 
BURGOS, E. Estratégias de Uso das Relativas em uma comunidade de fala afro-brasileira. 2003, 122f. Dissertação (Mestrado em Letras e Linguística) - Instituto de Letras, Universidade Federal da Bahia, Salvador, 2003.

KEENAN, E. L.; COMRIE, B. Noun phrase accessibility and universal grammar. Linguistic Inquiry, Cambridge, v. 8, n. 1, p. 63-99, 1977.

LABOV, W. Some sociolinguistic principles. In: PAULSTON, C. B.; TUCKER, G. R. Sociolinguistics: the essential readings. Massachusetts, Blackwell Publishing: 2003, p. 234250.

LUCCHESI, D. As duas grandes vertentes da história sociolingüística do Brasil (15002000), Revista D.E.L.T.A., São Paulo: v.17, n.1, p. 97-132, 2001. Disponível em: <http://www.scielo.br/pdf/delta/v17n1/a05v17n1.pdf>. Acesso em: 19/06/ 2016.

LUCCHESI, D. Contato entre línguas e mudança linguística: as orações relativas no português afro-brasileiro. In: FIGUEIREDO, C.; ARAÚJO, E. (Org.). Diálogos com Ribeiro: sobre gramáticas e história da língua portuguesa. Salvador: EDUFBA, 2015, p. 77-119.

MIOTO C.; SILVA, M. C. F.; LOPES, R. E. V. Novo manual de sintaxe. Florianópolis: Insular, 2004.

NEVES, M. H. de M. Gramática de usos do português. São Paulo: UNESP, 2000.

OLIVEIRA, J.; RIBEIRO, I. Estratégias de relativização em atas de afro-brasileiros do século XIX. In: FIGUEIREDO, C.; ARAÚJO, E. (Org.). Diálogos com Ribeiro: sobre gramáticas e história da língua portuguesa. Salvador: EDUFBA, p.149-173, 2015.

PROJETO A LÍNGUA PORTUGUESA DO SEMIÁRIDO BAIANO - FASE 3: A LÍNGUA FALADA EM FEIRA DE SANTANA. Disponível em: $<$ http://www2.uefs.br/nelp/fases_subprojetos.htm>. Acesso em 20/07/2020.

PROJETO CORPUS ELETRÔNICO DE DOCUMENTOS HISTÓRICOS DO SERTÃO (CE-DOHS). Disponível em: <http://www.tycho.iel.unicamp.br/cedohs/corpora_o.html>. Acesso em 10/07/2020.

RIBEIRO, I. As sentenças relativas. In: LUCCHESI, D. (Org.). O português afro-brasileiro. Salvador: EDUFBA, 2009. p. 185-208. ROCHA LIMA, Carlos Henrique. Gramática normativa da língua portuguesa. 24. ed. Rio de Janeiro: José Olympio, 1984.

RIBEIRO, I.; FIGUEIREDO, C. Relativas. In: OLIVEIRA, K.. África à Vista: Dez estudos sobre o português escrito por africanos no Brasil do século XIX. Salvador: EDUFBA, 2009. p. 208-240.

SILVA, J. C. da. As orações relativas no português falado em Feira de Santana-BA. 2018, 240 f. Dissertação (Mestrado em Estudos Linguísticos), Feira de Santana: Universidade Estadual da Bahia, 2018.

SILVA, J. C. da; FIGUEIREDO, C.; ARAÚJO, S. S. de F. As orações relativas no falar feirense: uma descrição preliminar. A cor das Letras, v. 17, p. 31-45, 2017. Disponível em: $<$ http://periodicos.uefs.br/index.php/acordasletras/article/view/1444>. Acesso em: 04/07/2020. 
SILVA, B. G. S. G. As estratégias de relativização na escrita de portugueses dos séculos XVI, XVII, XVIII. 2011, 207f. Tese (Doutorado em Língua Portuguesa). Rio de Janeiro: Universidade Federal do Rio de Janeiro.

SANKOFF, D.; TAGLIAMONTE, S.; SMITH, E. Goldvarb X: Computer program. Departament of Linguistics, University of Toronto, Canada. Disponível em $<$ http://individual.ca/tagliamonte/goldvarb/GV_index.htm. 2005>. Acesso em: 16/10/2011.

TARALLO, F. Diagnosticando uma gramática Brasileira: o português d'aquém e d'alémmar ao final do século XIX. In: ROBERTS, Ian; KATO, Mary (orgs). Português Brasileiro: uma viagem diacrônica. 2. ed. Campinas: Editora da UNICAMP, 1993 (versão original em inglês 1991). p. 69-100.

TARALLO, F. L. Relativization strategies in brazilian portuguese. (Estratégias de relativização no português brasileiro). 1983. 273 f. Tese (Doutorado em Linguística), Pensilvânia: Universidade da Pensilvânia, 1983.

WEINREICH, U.; LABOV, W.; HERZOG, M. Fundamentos empíricos para uma teoria da mudança linguística. Tradução de Marcos Bagno; revisão técnica de Carlos Alberto Faraco; posfácio de Maria da Conceição Paiva e Maria Eugênia L. Duarte. São Paulo: Parábola, 2006.

\section{AS AUTORAS E O PPGLinC}

\section{Silvana Silva de Farias Araújo}

Professora Titular de Língua Portuguesa do Departamento de Letras e Artes da Universidade Estadual de Feira de Santana (UEFS) atuando em cursos de Graduação e de Pós-Graduação. É egressa de Programas de Pós-Graduação da UFBA, sendo Doutora em Língua e Cultura (2014) e Mestre em Letras e Linguística (2005), sob orientação do Prof. Dr. Dante Lucchesi. Realizou dois estágios de Pós-doutoramento: um na Universidade Federal de Sergipe (UFS), com bolsa PDJ/CNPq, e outro na Universidade Federal do Rio de Janeiro (UFRJ).

É conselheira do Grupo de Estudos Linguísticos e Literários do Nordeste (GELNE) e membro do GT de Sociolinguística da ANPOLL. É Membro da Comissão Estratégica, na área de Línguas Ameaçadas, da ABRALIN. Coordenou o Programa de Pós-Graduação em Estudos Linguísticos (PPGEL/ UEFS), de 2016 a 2019, tendo presidido a comissão de elaboração do projeto do curso de Doutorado do referido Programa.

\section{Jéssica Carneiro da Silva}

É Professora Substituta de Linguística/Língua Inglesa na Universidade do Estado da Bahia (UNEB), campus II - Alagoinhas. Mestre em Estudos Linguísticos pelo Programa de Pós-Graduação em Estudos Linguísticos da Universidade Estadual 
de Feira de Santana, sob orientação da Profa. Dra. Silvana Silva de Farias Araújo (PPGEL/MEL/DLA/UEFS) e coorientada pela Profa. Dra. Cristina Figueiredo (PPGLinC/UFBA). Na dissertação, pesquisou sobre as orações relativas no português falado em Feira de Santana-BA e, desse modo, tem como subárea a Sociolinguística Variacionista, a teoria da mudança e da variação linguística. Foi aluna especial do Doutorado em Língua e Cultura no Programa de PósGraduação em Língua e Cultura pela Universidade Federal da Bahia (UFBA), fato que a estimulou a continuar estudando fenômenos linguísticos no português brasileiro. Graduada em Letras com Habilitação em Língua Inglesa, Língua Portuguesa e suas Respectivas Literaturas. Atualmente, é Professora Substituta na UNEB, lecionando nas áreas de Linguística e Língua Inglesa.

Nota do editor:

Artigo submetido para avaliação em: 16 de setembro de 2020.

Aprovado em sistema duplo cego em: 26 de fevereiro de 2021. 